\title{
Selectively high efficacy of eribulin against high-grade invasive recurrent and/or metastatic squamous cell carcinoma of the head and neck
}

\author{
YUTAKA KOBAYASHI $^{1}$, HIROKO KITAHARA ${ }^{1}$, MARIKO HIRAI $^{1}$, AKIRA TANAKA ${ }^{1}$, REI JOKAJI ${ }^{1}$, \\ KAZUHIKO KOBAYASHI ${ }^{1}$, GEORGE BOU-GHARIOS ${ }^{2}$, HIROYUKI NAKAMURA ${ }^{1}$ and SHUICHI KAWASHIRI ${ }^{1}$ \\ ${ }^{1}$ Department of Oral and Maxillofacial Surgery, Kanazawa University Graduate School of Medical Science, Kanazawa, \\ Ishikawa 920-8640, Japan; ${ }^{2}$ Department of Matrix Biology, Institute of Ageing and Chronic Disease, \\ University of Liverpool, Liverpool L7 8TX, UK
}

Received September 22, 2018; Accepted February 25, 2019

DOI: $10.3892 / \mathrm{ol} .2019 .10165$

\begin{abstract}
Patients with recurrent and/or metastatic squamous cell carcinoma of the head and neck (R/M SCCHN) have a poor prognosis. Over the past decade, a major development in the first-line treatment of R/M SCCHN was the introduction of cetuximab in combination with platinum plus 5-fluorouracil chemotherapy. Currently, a promising novel treatment option in $\mathrm{R} / \mathrm{M}$ SCCHN has emerged, termed immune checkpoint inhibitors. However, only a few patients presenting with R/M SCCHN have exhibited meaningful tumor regression with these agents. Therefore, novel agents are required to order improve the overall survival of patients with R/M SCCHN. Recently, we demonstrated that R/M SCCHN cells are highly sensitive to eribulin. In the present study, the effects of eribulin, paclitaxel and vinblastine were investigated in $\mathrm{R} / \mathrm{M}$ SCCHN (OLC-01 and OSC-19) and locally advanced SCCHN (OSC-20) cells. Tumour-inhibitory activities of eribulin against R/M SCCHN were evaluated in orthotopic xenograft models. The data revealed that eribulin has sub-nM growth inhibitory activities in vitro against OLC-01 cells, and that it is more potent than paclitaxel and vinblastine. The reduced expression of Tubulin Beta 3 Class III (TUBB3) following treatment was correlated with a high sensitivity to eribulin. Histological analysis of OLC-01 cells in NOD-SCID mice demonstrated that they had a higher invasiveness in the tissue
\end{abstract}

Correspondence to: Dr Hiroyuki Nakamura, Department of Oral and Maxillofacial Surgery, Kanazawa University Graduate School of Medical Science, 13-1 Takara-machi, Kanazawa, Ishikawa 920-8640, Japan

E-mail: hnak@me.com

Abbreviations: EMT, epithelial mesenchymal transition; LA, locally advanced; OS, overall survival; SCCHN, squamous cell carcinoma of the head and neck

Key words: eribulin, R/M SCCHN, TUBB3, orthotopic xenograft model around the alveolar cancer when compared with the histology of OSC-19 cells, which has been reported in our previous study. Treatment with eribulin revealed marked inhibitory activities in vivo at $0.125 \mathrm{mg} / \mathrm{kg}$ against OLC-01 cells orthotopic xenografts. In conclusion, the results highlight the existence of invasive-type heterogeneity in R/M SCCHN with respect to eribulin sensitivity. Eribulin is already an approved clinical agent; therefore, the continued investigation of its preclinical antitumor attributes may contribute significantly to the future process of identifying novel uses of eribulin against R/M SCCHN.

\section{Introduction}

Patients with recurrent and/or metastatic squamous cell carcinoma of the head and neck (R/M SCCHN) have a poor prognosis with a median overall survival (OS) time of less than 1 year (1). Cetuximab in combination with cisplatin/carboplatin and 5-fluorouracil, as a first-line treatment of R/M SCCHN, followed by maintenance treatment with cetuximab (EXTREME regimen) has exhibited the most favourable results with respect to overall response rates, progression-free survival and OS time $(2,3)$. A variation of this regimen permits the replacement of 5-fluorouracil with a taxane (e.g., docetaxel, paclitaxel) $(4,5)$. Meanwhile, immune checkpoint inhibitors have emerged as promising novel treatment options for $\mathrm{R} / \mathrm{M}$ SCCHN based on their positive results in clinical trials of second-line treatment $(6,7)$. These monoclonal antibodies targeting epidermal growth factor receptor or programmed death 1 (PD-1) were beneficial in palliative and curative treatments. However, few patients with R/M SCCHN exhibit meaningful tumour regression in response to these agents, and almost all responders develop acquired resistance against the tumour following 2-3 months of treatment (8). In addition, hyper-progression was noted in $29 \%$ of patients with $\mathrm{R} / \mathrm{M}$ SCCHN who received anti-PD-1 agents, and this finding was correlated with a shorter progression-free survival time (8). Hyper-progression was also observed in 39\% of patients with locoregional recurrence and in $9 \%$ of patients with only distant metastases (8). Therefore, inhibitors or molecules that disrupt 
known molecular pathways involved in R/M SCCHN are of particular interest, either as monotherapies or combination therapies.

Eribulin, and its mesylate salt (Halaven, Eisai), is an analogue of halichondrin $\mathrm{B}$, which is obtained from a marine sponge (9). As the first cancer therapeutic drug in the class halichondrin, eribulin acts by inhibiting microtubule dynamics and has a distinct mode of action against other tubulin-targeted agents (10-12). The drug specifically binds to the plus ends of microtubules with high affinity, resulting in the formation of short, non-functional tubulin aggregates that suppress microtubule dynamic stability and inhibit microtubule growth (13). This leads to mitotic arrest by disrupting the formation of normal mitotic spindles and subsequently leads to cancer cell apoptosis (10). Pre-clinically, eribulin exhibits potent activity towards various human cancer cell types in vitro and in vivo (9), exerting its anticancer effects by inducing irreversible mitotic blockade (14), subsequently leading to cancer cell apoptosis (13).

It has recently been demonstrated that R/M SCCHN cells were highly sensitive to eribulin in comparison with other SCCHN cell lines, and treatment with eribulin significantly enhanced the anti-proliferative effects of cetuximab (15). Eribulin is currently approved for the treatment of recurrent metastatic breast cancer, as it improves OS time in patients with late-stage metastatic disease (16). The present study evaluated eribulin as a novel therapeutic agent for R/M SCCHN.

\section{Materials and methods}

Cell culture. Three SCCHN cell lines established from biopsies of patients with R/M SCCHN or locally advanced SCCHN (LA-SCCHN) with different grades of invasiveness were used, including OLC-01 cells (R/M SCCHN, high-grade invasiveness), which were newly established in the present study, as well as the previously described OSC-19 (R/M SCCHN, intermediate-grade invasiveness) $(17,18)$ and OSC-20 cells (LA-SCCHN, low-grade invasiveness) (19). The OLC-01 cells were derived from a 62-year-old female with SCCHN, involving the maxillary gingiva and lower lip, high-grade invasiveness that had metastasised to the cervical lymph nodes and recurred frequently. Tissue samples were treated with $5 \%$ bacterial collagenase type I (Worthington Biochemical Corporation, Freehold, NJ, USA) for $1 \mathrm{~h}$ at $37^{\circ} \mathrm{C}$ and $0.02 \%$ trypsin (Thermo Fisher Scientific, Inc., Waltham, MA, USA) for $30 \mathrm{~min}$ at $37^{\circ} \mathrm{C}(17)$. Subsequently, the activities of the proteinases were blocked with $10 \%$ foetal bovine serum (FBS; Hyclone; GE Healthcare Life Sciences, Logan, UT, USA), the cells were seeded in culture dishes and maintained in Dulbecco's modified Eagle's medium(DMEM; Sigma-Aldrich; Merck KGaA, Darmstadt, Germany) containing 10\% FBS at $37^{\circ} \mathrm{C}$ in a humidified $5 \% \mathrm{CO}_{2}$ atmosphere. Cell clusters became attached to culture dishes in $24 \mathrm{~h}$ with an efficiency of $\sim 90 \%$. Cells began to grow continuously at 5 months following cultivation. No fibroblast outgrowth was observed. The doubling times of OLC-01 cells cultured on plastic dishes was $24.7 \mathrm{~h}$, and the OLC-01 cells had little intercellular connecting apparatus. OSC-19 (JCRB \#0198) and OSC-20 cells (JCRB \#0197) and normal human oral fibroblasts of the lip mucosa (KD; JCRB \#9103) were obtained from the JCRB Cell Bank
(Osaka, Japan). All cell lines were grown in DMEM (high glucose; Sigma-Aldrich; Merck KGaA) supplemented with $10 \%$ heat-inactivated $\mathrm{FBS}$ at $37^{\circ} \mathrm{C}$ in a humidified atmosphere containing $5 \% \mathrm{CO}_{2}$. Experiments using human samples were approved by the Ethics committee of the Kanazawa University Graduate School of Medical Science (IRB No. 352-2), and written informed consent was obtained from patients providing tissue specimens.

Proliferation assay. The three SCCHN cell lines were plated in 96-well plates and cultured with $0,0.01,0.1,1,5,10 \mathrm{nM}$ of eribulin, paclitaxel and vinblastine for 3 days respectively, followed by cell number and viability determinations using the CellTiter 96 AQueous One Solution Cell Proliferation Assay (Promega Corporation, Madison, WI, USA) according to the manufacturer's protocols. The optical density at $490 \mathrm{~nm}$ was measured using a microplate reader (iMark microplate reader; BioRad Laboratories, Inc., Hercules, CA, USA). Mean $\mathrm{IC}_{50}$ values were calculated based on those generated from separate sigmoidal curves representing the growth inhibition activity vs. eribulin, paclitaxel and vinblastine in three independent experiments. Eribulin was purchased from Eisai Co., Ltd. (Tsukuba, Japan). Vinblastine and paclitaxel (Taxol) were purchased from Nihon Kayaku (Tokyo, Japan). The data are presented as the mean \pm SEM.

RNA extraction, cDNA synthesis, and quantitative reverse transcription-quantitative polymerase chain reaction $(R T-q P C R)$. The mRNA expression levels of TUBB, TUBB2A, TUBB3, TUBB4B and TUBB6 in the three SCCHN cell lines treated with eribulin, paclitaxel and vinblastine at concentration of $\mathrm{IC}_{50}$ or the control vehicle-treated SCCHN cells were analysed using a Rotor-Gene Q 2plex System (Qiagen, Hilden, Germany) with FAM/ZEN/IBFQ labelled TaqMan probes (Integrated DNA Technologies Inc., Coralville, IA, USA; DNA sequences not available). Total RNA was extracted from the SCCHN cells using TRI Reagent (Merck KGaA) and a PureLink RNA Mini kit (Thermo Fisher Scientific, Inc.). cDNA was obtained using a PrimeScript 1st strand cDNA Synthesis kit (Takara Biotechnology, Inc., Tokyo, Japan). All reactions were performed in accordance with the manufacturer's protocol. For the $\Delta \Delta \mathrm{Ct}$ method for quantitative real-time PCR (qPCR) to be valid, the efficiency of the target amplification and the efficiency of the reference amplification must be approximately equal. Therefore, the present study analysed HPRT1, B2M, TBP, GUSB, ACTB, POLR2A, RPLP0, PPIA and $18 \mathrm{~S}$ rRNA as potential internal standards for analysing TUBB, TUBB2A, TUBB3, TUBB4B and TUBB6 expression. Based on these validation experiment, we selected PPIA as an internal standard using HEX/ZEN/IBFQ labelled TaqMan probes (Integrated DNA Technologies Inc.; DNA sequences not available). Relative expression levels were calculated using the $\Delta \Delta C q$ method for qPCR (20), which presents the data as fold differences in expression relative to a calibrator sample, in this case represented by the mean expression of three experimental measurements of PPIA in the control or control vehicle-treated cells.

Western blot analysis. Total protein was extracted from the three SCCHN cell lines treated with eribulin, paclitaxel and 
vinblastine at concentration of $\mathrm{IC}_{50}$ or the control vehicle-treated SCCHN cells. The concentration of total extracted protein was measured using the Fluorescence Qubit Protein assay in accordance with the manufacturer's protocol (Thermo Fisher Scientific, Inc.). An equal amount (30 $\mu \mathrm{g}$ of protein) of lysate or culture medium was mixed with loading buffer and then electrophoretically separated using 10\% SDS-PAGE gel and transferred onto PVDF membranes. The membranes were blocked with Blocking One (Nacalai Tesque, Kyoto, Japan) for $10 \mathrm{~min}$ at room temperature, followed by incubation with anti-TUBB3 (cat. no. 52623; Abcam, Tokyo, Japan) and anti-human GAPDH antibodies (cat. no. M171-3; MBL, Tokyo, Japan). Following washing with tris-buffered saline containing $0.05 \%$ Tween, the membranes were incubated with horseradish peroxidase-conjugated anti-mouse IgG (cat. no. 7076; Cell Signalling Technology, Inc., Danvers, MA, USA). After washing with tris-buffered saline- $0.05 \%$ Tween, membranes were incubated with the ECL Prime Western Blotting Detection Reagent (GE Healthcare, Little Chalfont, UK). Signals were detected and analysed using C-DiGit (M\&S TechnoSystems, Tokyo, Japan).

In vivo orthotopic xenograft studies. The anticancer effects of eribulin, paclitaxel and vinblastine were evaluated in OLC-01 human R/M SCCHN xenograft models using 5-6 week-old female NOD-SCID mice (NOD. CB17-Prkdc ${ }^{\text {scid }} / \mathrm{J}$, Charles River Japan, Yokohama, Japan). The mice were housed at $22 \pm 2^{\circ} \mathrm{C}$, ammonia $\leq 14 \mathrm{ppm}, 12$-h light/12-h dark cycle, free access to food and water and free from microbial pathogens at the Animal Center of Kanazawa University (Kanazawa, Japan). All of the studies using laboratory animals were approved by the Institutional Animal Care and Use Committees of Kanazawa University (permit No. AP183935), and the protocols adhered to all applicable institutional and governmental guidelines for the humane care and use of laboratory animals. At three days prior to drug administration, $1 \times 10^{6}$ OLC- 01 cells were injected submucosally into the tongues of mice. Eribulin, paclitaxel and vinblastine were administered intravenously at concentrations of 0.125 and $0.5 \mathrm{mg} / \mathrm{kg}$ body weight three times at intervals of 2 days (q2d x 3). On day 7, the mice were sacrificed by intraperitoneal administration of $100 \mathrm{mg} / \mathrm{kg}$ Nembutal (Dainippon Sumitomo Pharma Co., Ltd, Osaka, Japan) due to the high tumour load and feeding difficulties. The maximum size the tumours were permitted to grow to was $56.8 \mathrm{~mm}^{3}$. Soft food (DietGel 76A, ClearH20, Portland, $\mathrm{ME}$ ) was placed on the cage floor every day following the inoculation of cells until sacrifice. Each group consisted of six mice. Tumour volumes were determined via calliper measurements and calculated using the formula $V=0.67 \pi[(L$ $+W) / 4]^{3}$ [i.e., volume $(V)$ of a semisphere with a diameter equal to the mean of tumour length $(L)$ and width $(W)](9)$. Body weights and water consumption were measured in all experiments to assess toxicity.

Each tumour specimen was fixed in $10 \%$ buffered formalin for $16 \mathrm{~h}$ at room temperature and embedded in paraffin to prepare $4 \mu \mathrm{m}$-thick sections. The sections were stained with haematoxylin for $3 \mathrm{~min}$ and eosin for $30 \mathrm{sec}$ at room temperature. The stained sections were then observed under a light microscope (magnification, $\mathrm{x} 100$ ).
Table I. The effects of microtubule inhibitors on SCCHN cell lines.

\begin{tabular}{lccc}
\hline & \multicolumn{3}{c}{$\mathrm{IC}_{50}(\mathrm{nM})$} \\
\cline { 2 - 4 } Drug & OSC-20 & OSC-19 & OLC-01 \\
\hline Eribulin & $5.673(1.765)$ & $0.512(0.060)$ & $0.063(0.008)$ \\
Paclitaxel & $6.924(0.513)$ & $6.224(0.779)$ & $3.366(0.419)$ \\
Vinblastine & $3.263(0.372)$ & $0.511(0.058)$ & $0.534(0.114)$ \\
\hline
\end{tabular}

Values are expressed as the mean (SEM).

Statistical analysis. The data are presented as the mean \pm standard error of the mean. For comparisons between samples, data were analysed by one-way analysis of variance and Tukey's multiple comparison tests using SPSS, version 23 (IBM Corp., Armonk, NY, USA). P $<0.05$ was considered to indicate a statistically significant difference.

\section{Results}

Inhibition of human R/M SCCHN cell growth in vitro. The present study examined the effects of eribulin on the proliferation of three SCCHN cell lines. On the basis of the known anti-tubulin mechanism of eribulin (21), the in vitro growth inhibitory effects of eribulin were compared with those of the microtubule stabiliser paclitaxel and microtubule destabiliser vinblastine (Fig. 1). The $\mathrm{IC}_{50}$ of eribulin in OLC-01 cells was $0.063 \pm 0.008$, compared with $0.512 \pm 0.06$ and $5.673 \pm 1.765 \mathrm{nM}$ in OSC-19 and OSC-20 cells, respectively (Fig. 1 and Table I). In OLC-01 cells, eribulin inhibited cell growth with greater potency than paclitaxel $(3.366 \pm 0.419 \mathrm{nM})$ or vinblastine $(0.534 \pm 0.114 \mathrm{nM})$ (Fig. 1 and Table I) . In OSC-19 cells, eribulin had greater potency than paclitaxel $(6.224 \pm 0.779 \mathrm{nM})$ (Fig. 1 and Table I). Meanwhile, OSC-20 cells were approximately $10-50$-fold less sensitive to eribulin and vinblastine than OLC-01 and OSC-19 cells, a difference that was not observed for paclitaxel (Fig. 1 and Table I).

Eribulin decreased TUBB3 expression in OLC-O1 cells. $\beta$-tubulin subunits affect microtubule polymer mass and/or drug binding, and they are associated with resistance to tubulin-binding agents (22-24). Previous research using gene expression profiling revealed that the TUBB, TUBB2A, TUBB3, TUBB4B and TUBB6 genes can selectively differentiate eribulin-sensitive several cancer cells (25). Therefore, the differences in of the expression of these $\beta$-tubulin subunits in SCCHN cells were analysed by RT-qPCR in order to analyse the mechanism of high sensitivity of OLC-01 cells to eribulin, as presented in Fig. 1 and Table I. In OLC-01 cells, TUBB3 levels were 1.9-, 2.0- and 1.5-fold higher than those in OSC-19, OSC-20 and KD cells, respectively (Fig. 2A). In addition, TUBB4 levels were markedly higher in OLC-01 cells than in KD cells. By contrast, TUBB and TUBB2A expression in OLC-01 was 0.46- and 0.55-fold lower, respectively, than that in KD cells. TUBB4B expression was 1.73 -fold higher in OSC-19 cells than in KD cells. In addition, the levels 
A

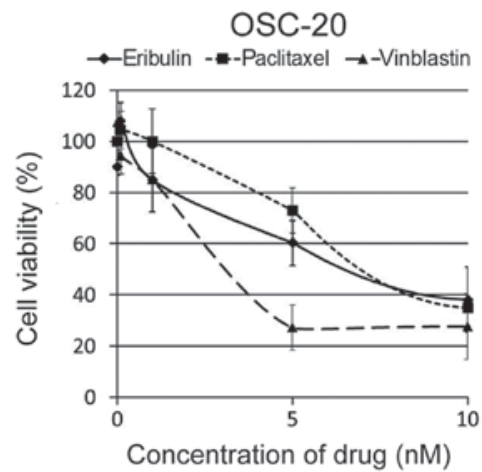

OLC-01

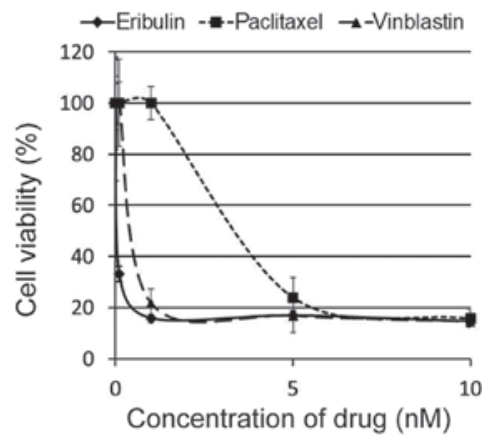

B

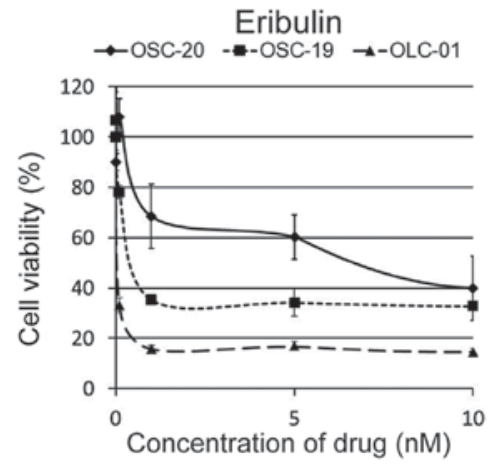

Vinblastin

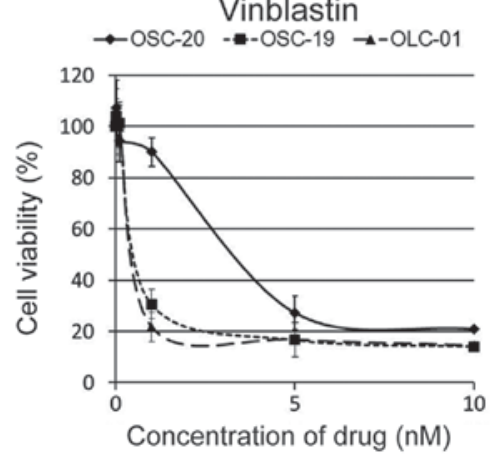

OSC-19

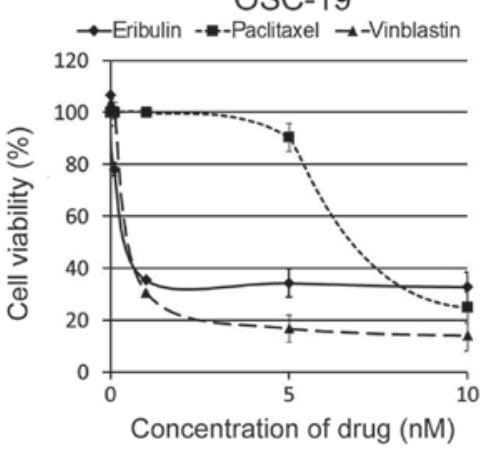

Paclitaxel

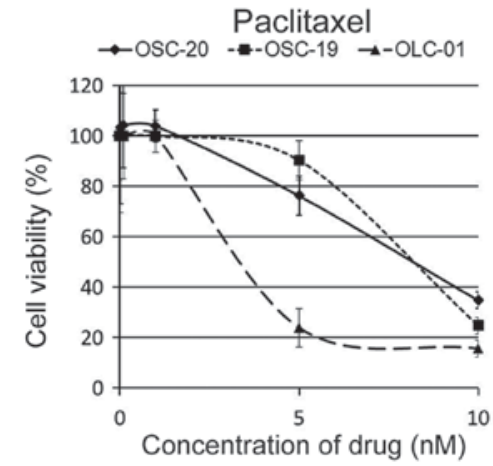

Figure 1. Inhibition of human SCCHN cell growth in vitro using eribulin, paclitaxel and vinblastin. (A) The growth inhibitory effects of OLC-01 cells treated with eribulin, paclitaxel and vinblastin were compared with those of OSC-20 and OCC-19 cells. The data are presented as the mean \pm standard error of the mean from triplicate experiments. (B) The growth inhibitory effects of eribulin against three human SCCHN cell lines were compared with those of the microtubule stabiliser paclitaxel and microtubule destabiliser vinblastine. The data are presented as the mean \pm standard error of the mean from triplicate experiments. SCCHN, squamous cell carcinoma of the head and neck.

of TUBB2A and TUBB4B in OSC-20 cells were 1.7- and 2.42-fold higher, respectively, than those in KD cells (Fig. 2A).

As presented in Fig. 2B, TUBB3 and TUBB levels in OLC-01 cells were significantly decreased under eribulin treatment compared with the control levels. Conversely, the expression of five $\beta$-tubulin subunits (TUBB, TUBB2A,
TUBB3, TUBB4B and TUBB6) in OSC-19 cells and four $\beta$-tubulin subunits (TUBB, TUBB3, TUBB4B and TUBB6) in OSC-20 cells were significantly increased following eribulin treatment. There was large variation in the fold changes in the individual cell lines under paclitaxel treatment; however, the expression of the majority of $\beta$-tubulin subunits was 
A

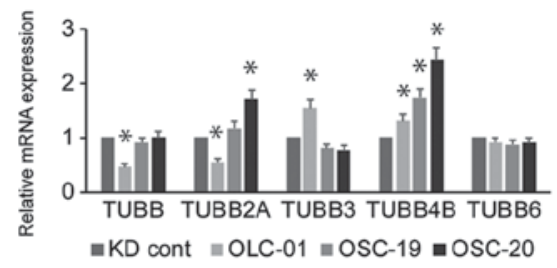

C
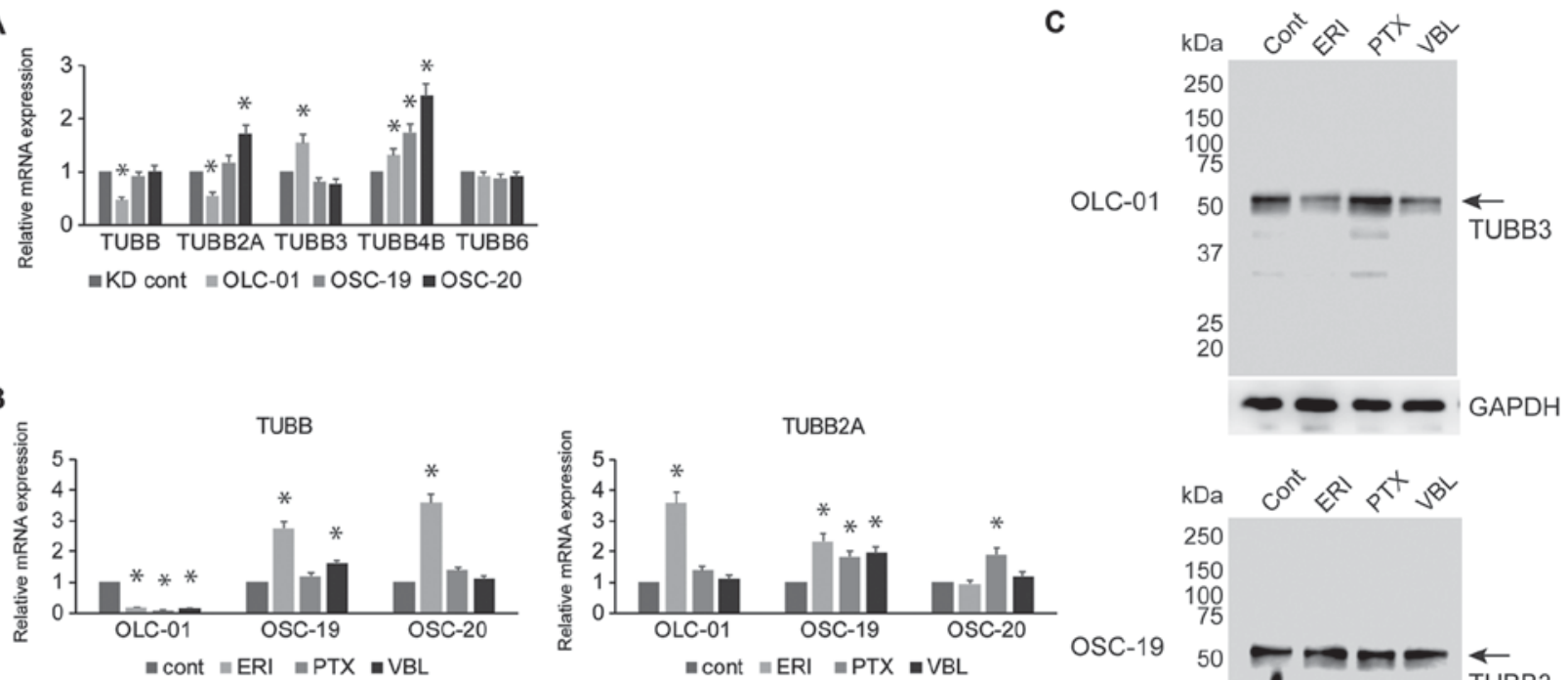

TUBB3
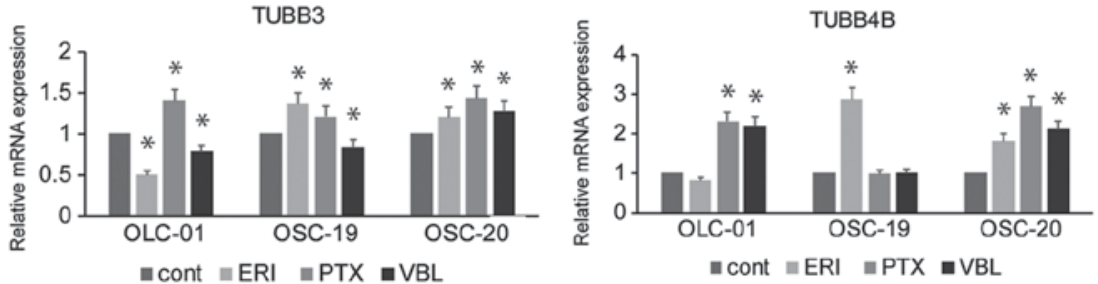

TUBB2A
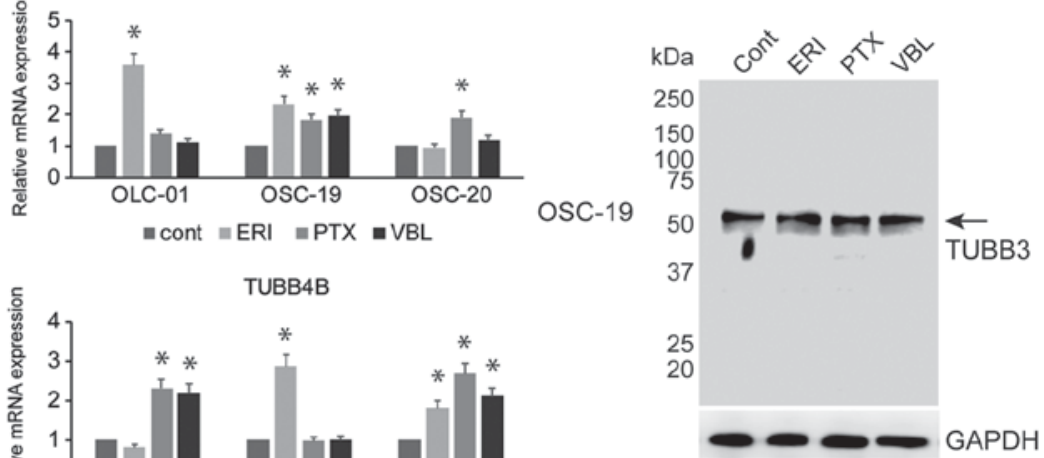

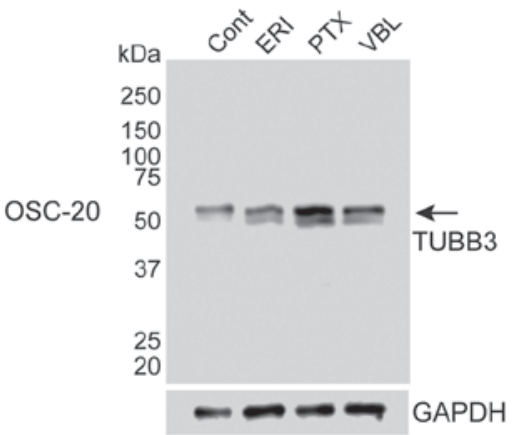

Figure 2. TUBB, TUBB2A, TUBB3, TUBB4B and TUBB6 expression in squamous cell carcinoma of the head and neck cell lines. (A) RT-qPCR of TUBB, TUBB2A, TUBB3, TUBB4B and TUBB6 mRNA derived from OLC-01, OSC-19 and OSC-20 cells, presented as fold changes relative to the expression in KD cells. ${ }^{*} \mathrm{P}<0.05$ vs. control KD cells. (B) RT-qPCR of TUBB, TUBB2A, TUBB3, TUBB4B and TUBB6 mRNA derived from untreated and eribulin-, paclitaxelor vinblastine-treated OLC-01, OSC-19 and OSC-20 cells. Data are presented as fold changes in treated cells relative to the expression in untreated control cells. ${ }^{*} \mathrm{P}<0.05$ vs. control vehicle-treated OLC-01, OSC-19 and OSC-20 cells. (C) Immunoblot of untreated and eribulin-, paclitaxel or vinblastine-treated lysates of OLC-01, OSC-19, and OSC-20 cells using antibodies against TUBB3. GAPDH served as the loading control. RT-qPCR, reverse transcription-quantitative polymerase chain reaction analysis; Cont, control; ERI, eribulin; PTX, paclitaxel; VBL, vinblastine.

significantly increased by $>1.3$-fold in the three cell lines. Similarly, TUBB3 expression was significantly decreased by vinblastine treatment in OLC-01 and OSC-19 cells vs. the control (Fig. 2B). As illustrated in Fig. 2C, western blot analysis revealed that TUBB3 expression was downregulated in eribulin- or vinblastine-treated OLC-01 cells compared with those in OSC-19 and OSC-20 cells. In addition, treatment with paclitaxel upregulated TUBB3 expression in all three SCCHN cell lines.

Inhibition of human SCCHN orthotopic xenograft tumour growth in vivo. The abilities of eribulin to inhibit tumour growth in vivo were examined in human SCCHN orthotopic xenograft models created using OLC-01 cells (Fig. 3). On day 7, treatment with $0.125-0.5 \mathrm{mg} / \mathrm{kg}$ eribulin led to $>95 \%$ growth inhibition compared with the findings in untreated tumours (Fig. 3A and B). Contrarily, paclitaxel had weaker growth inhibitory effects at these concentrations on day 7; and no measurable effects were observed at $0.125 \mathrm{mg} / \mathrm{kg}$, whereas the concentration of $0.5 \mathrm{mg} / \mathrm{kg}$ inhibited growth by $54.6 \%$ compared with the untreated control (Fig. 3A and B). Meanwhile, treatment with $0.125-0.5 \mathrm{mg} / \mathrm{kg}$ vinblastine inhibited tumour growth by $35.5-73.3 \%$ vs. the control (Fig. 3A and B). There was no evidence of toxicity based on body weight or water consumption (data not shown). As presented in Fig. 3C, histologic analysis of OLC-01 cells implanted into NOD-SCID mice revealed that cord-like small alveolar tumour lesions had greater diffusion and invasion into the tissue surrounding the tumour than previously reported for OSC-19 cells (18). In addition, tumours treated with eribulin alone displayed increasing numbers of abnormal mitotic cells (arrowheads) (26,27), suggesting that eribulin may have an inhibitory effect on the microtubule dynamics of tumour cells. Tumour necrosis was identified only in the eribulin group (arrows). Haematoxylin and eosin staining revealed no pathological changes in the untreated, paclitaxel and vinblastine groups (Fig. 3C). 
A
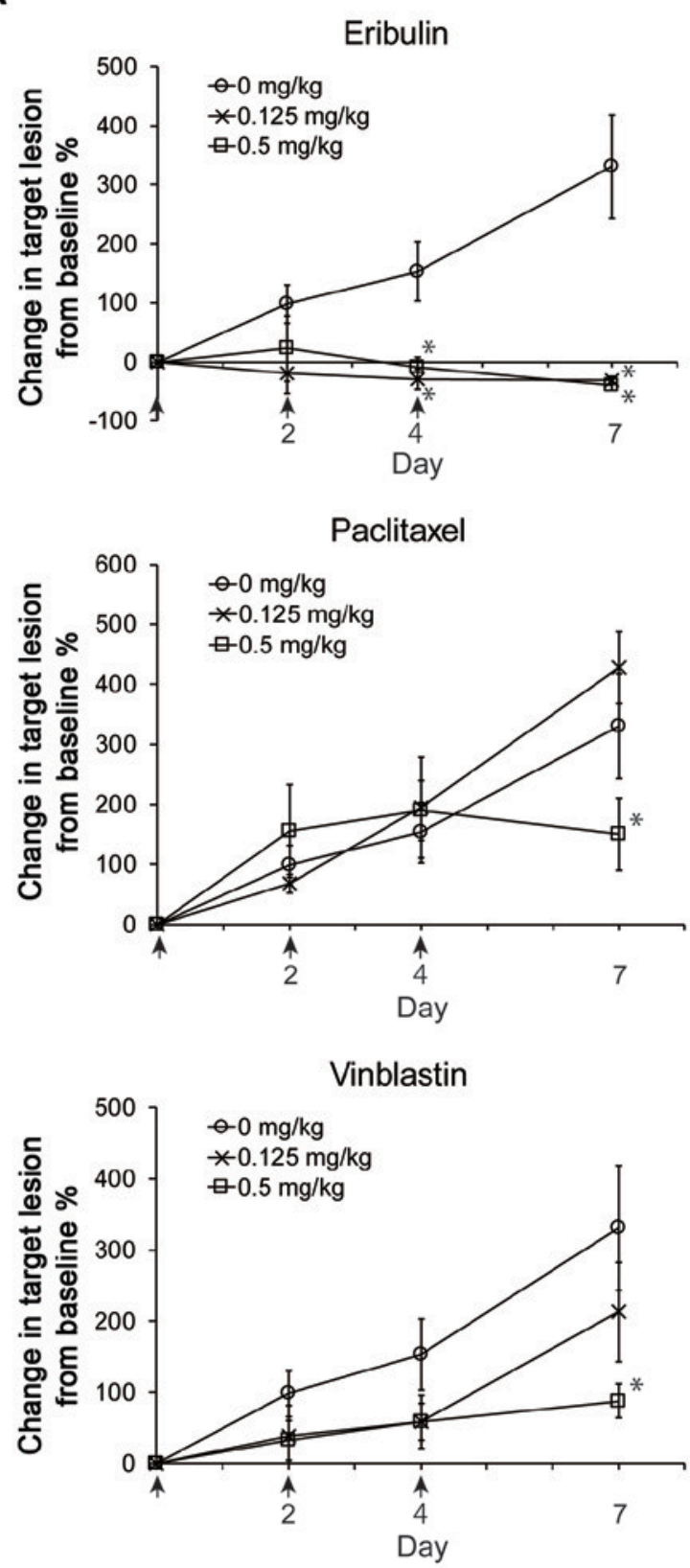

B

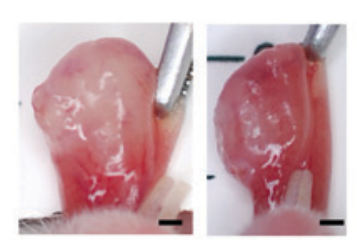

Paclitaxel

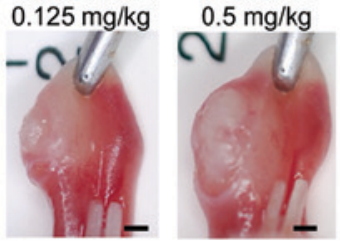

C

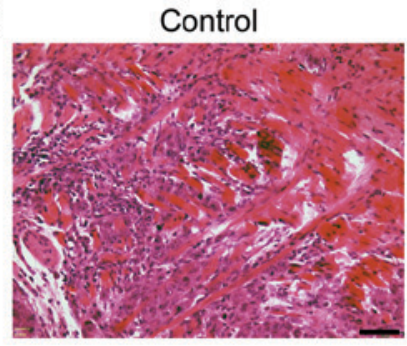

Paclitaxel $0.125 \mathrm{mg} / \mathrm{kg}$

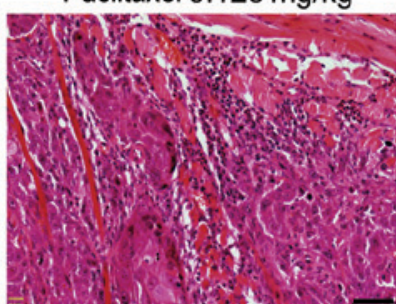

Eribulin

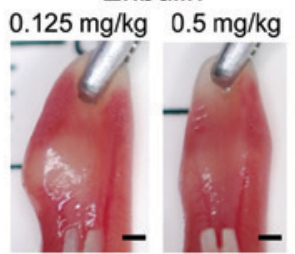

Vinblastin
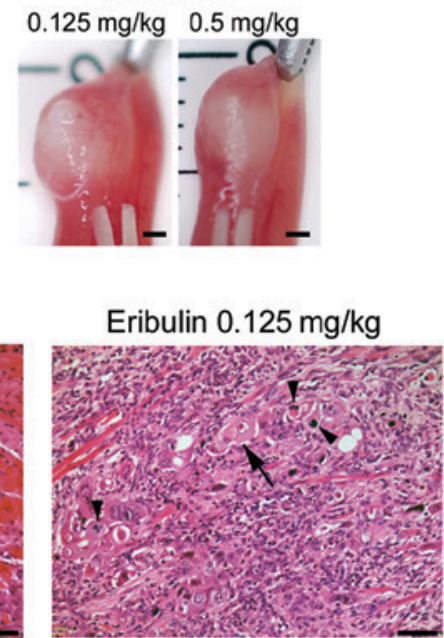

Vinblastin $0.125 \mathrm{mg} / \mathrm{kg}$

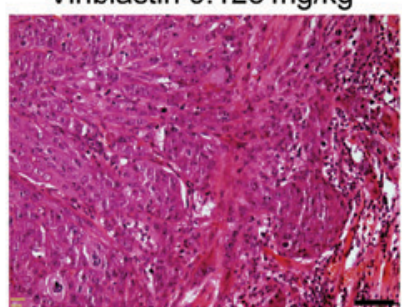

Figure 3. Inhibition of human squamous cell carcinoma of the head and neck xenograft growth in vivo by eribulin. (A) Antitumor activity of eribulin, paclitaxel or vinblastine was evaluated against OLC-01 xenografts using the indicated concentrations. Dosing days for drugs are illustrated with arrows below the X-axes. Plotted mean change in the target lesion from baseline (\%) following the onset of complete remission. Results are presented as the mean \pm SEM. ${ }^{*} \mathrm{P}<0.05$ vs. $0 \mathrm{mg} / \mathrm{kg}$. (B) Representative tongue images at the end of the treatment schedule. Scale bar, $1 \mathrm{~mm}$. (C) Representative H\&E-stained histological images of OLC-01 xenografts at the end of the treatment schedule. Abnormal mitotic cells are denoted by arrow heads. Necrosis is indicated by arrows. Scale bar, $50 \mu \mathrm{m}$.

\section{Discussion}

The traditional approach to drug discovery involves the de novo identification and validation of novel molecular entities, which is a time-consuming and costly process. Drug repositioning, the process of identifying novel uses for existing drugs, has gained popularity in recent years. Recently, we demonstrated that R/M SCCHN cells were highly sensitive to eribulin in comparison with other SCCHN cell lines (15), leading us to examine the efficacy of the drug against this malignancy in the present study.

In previous in vitro studies, cell growth was observed to be inhibited by eribulin $\left(\mathrm{IC}_{50}=0.09-9.5 \mathrm{nM}\right)$ in a wide variety of established human cancer cell lines, including breast, non-small cell lung, small cell and ovarian cancer cell lines $(9,28)$. In these reports, eribulin was observed to inhibit MDA-MB-435 cell growth $\left(\mathrm{IC}_{50}=0.09 \mathrm{nM}\right)$ with greater potency than vinblastine $\left(\mathrm{IC}_{50}=0.59 \mathrm{nM}\right)$ or paclitaxel $\left(\mathrm{IC}_{50}=2.5 \mathrm{nM}\right)(9)$, which were in line with the findings of the present study. Meanwhile, the sensitivity of OSC-19 and OSC-20 cells to eribulin in the present study was similar or lower than that previously reported for breast cancer cells (9). Additional studies are necessary to elucidate the precise molecular mechanisms governing this selective eribulin sensitivity.

Eribulin binds near a region called the Vinca-binding domain of $\beta$-tubulin at microtubule plus ends (22). The binding site for paclitaxel is located in a $\beta$-tubulin subunit on the whole 
inner surface of the microtubule (23). Vinblastine binds to a subunit of $\beta$-tubulin dimers on the whole outside surface of the microtubule (24). These differences in the drug binding region may be linked to alterations of the $\beta$-tubulin expression profile, particularly changes in expression of the TUBB3 isotype, and drug sensitivity. Of note, Wilson et al (29) reported that eribulin had an increased binding affinity for microtubules in the absence of TUBB3. TUBB3 is primarily expressed in neurons and the testes (30). The potential association of TUBB3 overexpression with cancer aggressiveness or metastasis has been reported for several cancer types, including non-small-cell lung cancer (31), breast cancer (32), urinary bladder cancer (33) and oesophageal adenocarcinoma (34). Notably, Nienstedt et al (35) reported that TUBB3 is over-expressed in the majority of head and neck cancers; however, this expression is not associated with clinical outcome. The precise role of TUBB3 in R/M SCCHN prior to eribulin treatment is unclear. However, previous studies have demonstrated that $\alpha$ - and $\beta$-tubulin synthesis is auto-regulated by post-transcriptional mechanisms that can alter tubulin mRNA levels in response in the unassembled tubulin subunit concentration (36). Based on these findings, the uregulation of tubulin expression by paclitaxel observed in the present study is likely driven by a compensatory mechanism to increase the supply of tubulin monomers depleted by microtubule polymerisation, whereas the downregulation of tubulin expression by eribulin may be explained by the opposite effect of increasing the number of tubulin monomers by inhibiting microtubule polymerisation (37). Consequently, it is reasonable to infer that sensitivity to eribulin may be associated with the downregulation of TUBB3 expression rather than the heterogeneous expression level of TUBB3 in patients with R/M SCCNH prior to eribulin treatment.

Previous studies of human tumour xenograft studies in mice, including breast, lung, ovary, colon, melanoma, pancreatic and fibrosarcoma, have demonstrated tumour regression, remission and an increased lifespan at concentrations below the maximum tolerated dose of eribulin $(9,28)$. Eribulin exhibits significant and superior in vivo anticancer efficacy in MDA-MB-435, COLO 205 and LOX cells at much lower concentrations $(0.05-1 \mathrm{mg} / \mathrm{kg}$ i.v. or i.p.) than paclitaxel. All concentrations of eribulin used in the OLC-01 xenograft model in the present study were equally efficacious $(0.125,0.5 \mathrm{mg} / \mathrm{kg})$ to those in an MDA-MB-435 model $(9,28)$. Despite the excellent sensitivity of R/M SCCNH cells to the drug in the present study, a Phase II study of eribulin in patients with R/M SCCHN did not reveal significant efficacy (38). A multi-centre Phase II trial evaluating the response to eribulin in patients with $\mathrm{R} / \mathrm{M}$ SCCHN was conducted in conjunction with the NCI (38). In total, 40 eligible patients with a median age of 61.2 years were enrolled, 33 (83\%) of whom had metastatic disease. The primary tumour sites included the oropharynx, lip/oral cavity, larynx, hypopharynx, other/unknown and nasopharynx in 15, 12, 6, 4, 2 and 1 patient(s), respectively. The best response to eribulin was stable disease/no response in $48 \%$ of patients, whereas disease worsening was noted in $48 \%$ of patients. In total, $5 \%$ of patients had a confirmed partial response, and $3 \%$ had an unconfirmed partial response. OSC-19 cells were established from tumour biopsies of patients with R/M SCCHN $(17,18)$. In addition, OLC-01 cells established from tumour biopsies of patients with $\mathrm{R} / \mathrm{M}$ SCCHN in this previous study were more invasive than OSC-19 cells $(17,18)$. Indeed, the histology of OLC-01 xenografts in NOD-SCID mice in the present study was in line with previous findings (18). These data suggested that eribulin had selectively high efficacy against R/M SCCHN cells with high invasiveness. At present, it is unclear whether patients enrolled in a recent Phase II trial had high-grade invasive $\mathrm{R} / \mathrm{M}$ SCCHN (38). Alternatively, eribulin treatment converted R/M SCCHN cells into an epithelial phenotype, as reported in our previous study (15), whereas OSC-20 cells, which possess an epithelial phenotype, exhibited eribulin resistance in the present study. These results suggested that eribulin sensitivity decreases during mesenchymal-to-epithelial transition. To completely inhibit R/M SCCHN tumour growth, combination therapy consisting of eribulin plus cetuximab may be useful due to eribulin sensitising R/M SCCHN cells to cetuximab via induction of mesenchymal-to-epithelial transition as demonstrated previously (15).

In conclusion, the results of the present study suggest the existence of invasive-type heterogeneity in R/M SCCHN with respect to eribulin sensitivity, suggesting that further studies comparing characteristics of SCCHN models as a function of eribulin sensitivity may illuminate potential biomarker approaches for defining eribulin sensitivity and resistance. As a clinically approved drug, the continued investigation of the preclinical antitumor attributes of eribulin may significantly contribute to future progress in identifying novel uses of eribulin against R/M SCCHN.

\section{Acknowledgements}

Not applicable.

\section{Funding}

The present study was supported by Grants-in-Aid for Scientific Research from the Ministry of Education, Science, Sports, and Culture, Japan (grant nos. 17K11870, 18K17221, 18K17166, 17K11869, 15H05042). The funders had no role in the study design, data collection and analysis, decision to publish, or preparation of the manuscript.

\section{Availability of data and materials}

All data generated or analyzed during this study are included in this published article.

\section{Authors' contributions}

HN was responsible for conception and design of the analyses; YK, HK, MH, AT, RJ and KK conducted experiments; YK and $\mathrm{HN}$ wrote the manuscript; GBG and SK provided conceptual advice; HN edited the manuscript; All authors approved the final version of this manuscript.

\section{Ethics approval and consent to participate}

Experiments using human samples were approved by the ethics committee of the Kanazawa University Graduate School of Medical Science (IRB No. 352-2), and written informed 
consent was obtained from patients providing tissue specimens. The study was performed in accordance with the Declaration of Helsinki. All of the studies using laboratory animals were approved by the Institutional Animal Care and Use Committees of Kanazawa University (permit no. AP183935), and the protocols adhered to all applicable institutional and governmental guidelines for the humane care and use of laboratory animals.

\section{Patient consent for publication}

Not applicable.

\section{Competing interests}

The authors declare that they have no competing interests.

\section{References}

1. Price KA and Cohen EE: Current treatment options for metastatic head and neck cancer. Curr Treat Options Oncol 13: 35-46, 2012.

2. Vermorken JB and Specenier P: Optimal treatment for recurrent/metastatic head and neck cancer. Ann Oncol 21 (Suppl): vii252-vii261, 2010.

3. Vermorken JB, Mesia R, Rivera F, Remenar E, Kawecki A, Rottey S, Erfan J, Zabolotnyy D, Kienzer HR, Cupissol D, et al: Platinum-based chemotherapy plus cetuximab in head and neck cancer. N Engl J Med 359: 1116-1127, 2008.

4. Guigay J, Fayette J, Dillies AF, Sire C, Kerger JN, Tennevet I, Machiels JP,Zanetta S, Pointreau Y,Bozec Le Moal L, et al: Cetuximab, docetaxel, and cisplatin as first-line treatment in patients with recurrent or metastatic head and neck squamous cell carcinoma: A multicenter, phase II GORTEC study. Ann Oncol 26: 1941-1947, 2015.

5. Tahara M, Kiyota N, Yokota T, Hasegawa Y, Muro K, Takahashi S, Onoe T, Homma A, Taguchi J, Suzuki M, et al: Phase II trial of combination treatment with paclitaxel, carboplatin and cetuximab (PCE) as first-line treatment in patients with recurrent and/or metastatic squamous cell carcinoma of the head and neck (CSPOR-HN02). Ann Oncol 29: 1004-1009, 2018.

6. Ferris RL, Blumenschein G Jr, Fayette J, Guigay J, Colevas AD, Licitra L, Harrington KJ, Kasper S, Vokes EE, Even C, et al: Nivolumab for recurrent squamous-cell carcinoma of the head and neck. N Engl J Med 375: 1856-1867, 2016.

7. Harrington KJ, Ferris RL, Blumenschein G Jr, Colevas AD, Fayette J, Licitra L, Kasper S, Even C, Vokes EE, Worden F, et al: Nivolumab versus standard, single-agent therapy of investigator's choice in recurrent or metastatic squamous cell carcinoma of the head and neck (CheckMate 141): Health-related quality-of-life results from a randomised, phase 3 trial. Lancet Oncol 18: 1104-1115, 2017.

8. Saada-Bouzid E, Defaucheux C, Karabajakian A, Coloma VP, Servois V, Paoletti X, Even C, Fayette J, Guigay J, Loirat D, et al: Hyperprogression during anti-PD-1/PD-L1 therapy in patients with recurrent and/or metastatic head and neck squamous cell carcinoma. Ann Oncol 28: 1605-1611, 2017.

9. Towle MJ, Salvato KA, Budrow J, Wels BF, Kuznetsov G, Aalfs KK, Welsh S, Zheng W, Seletsky BM, Palme MH, et al: In vitro and in vivo anticancer activities of synthetic macrocyclic ketone analogues of halichondrin B. Cancer Res 61: 1013-1021, 2001.

10. Jordan MA, Kamath K, Manna T, Okouneva T, Miller HP, Davis C, Littlefield BA and Wilson L: The primary antimitotic mechanism of action of the synthetic halichondrin E7389 is suppression of microtubule growth. Mol Cancer Ther 4: 1086-1095, 2005.

11. Okouneva T, Azarenko O, Wilson L, Littlefield BA and Jordan MA: Inhibition of centromere dynamics by eribulin (E7389) during mitotic metaphase. Mol Cancer Ther 7: 2003-2011, 2008.

12. Smith JA, Wilson L, Azarenko O, Zhu X, Lewis BM, Littlefield BA and Jordan MA: Eribulin binds at microtubule ends to a single site on tubulin to suppress dynamic instability. Biochemistry 49: 1331-1337, 2010

13. Kuznetsov G, Towle MJ, Cheng H, Kawamura T, TenDyke K, Liu D, Kishi Y, Yu MJ and Littlefield BA: Induction of morphological and biochemical apoptosis following prolonged mitotic blockage by halichondrin B macrocyclic ketone analog E7389. Cancer Res 64: 5760-5766, 2004.
14. Towle MJ, Salvato KA, Wels BF, Aalfs KK,Zheng W, Seletsky BM, Zhu X, Lewis BM, Kishi Y, Yu MJ and Littlefield BA: Eribulin induces irreversible mitotic blockade: Implications of cell-based pharmacodynamics for in vivo efficacy under intermittent dosing conditions. Cancer Res 71: 496-505, 2011.

15. Kitahara H, Hirai M, Kato K, Bou-Gharios G, Nakamura H and Kawashiri S: Eribulin sensitizes oral squamous cell carcinoma cells to cetuximab via induction of mesenchymal-to-epithelial transition. Oncol Rep 36: 3139-3144, 2016.

16. Kaufman PA, Awada A, Twelves C, Yelle L, Perez EA, Velikova G, Olivo MS, He Y, Dutcus CE and Cortes J: Phase III open-label randomized study of eribulin mesylate versus capecitabine in patients with locally advanced or metastatic breast cancer previously treated with an anthracycline and a taxane. J Clin Oncol 33: 594-601, 2015.

17. Yokoi T, Homma $\mathrm{H}$ and Odajima T: Establishment and characterization of OSC-19 cell line in serum and protein free culture. Tumor Res 24: 1-17, 1988

18. Kawashiri S, Noguchi N, Tanaka A, Nakaya H, Kato K and Yamamoto E: Inhibitory effect of neoadjuvant chemotherapy on metastasis of oral squamous cell carcinoma in a mouse model. Oral Oncol 45: 794-797, 2009.

19. Yokoi T, Hirata S, Nishimura F, Miyakawa A, Odajima T and Kohama G: Some properties of a newly established human cell line derived from an oral squamous carcinoma. Tumor Res 25: 93-91-93, 1990

20. Livak KJ and Schmittgen TD: Analysis of relative gene expression data using real-time quantitative PCR and the 2(-Delta Delta C(T)) method. Methods 25: 402-408, 2001.

21. Jordan MA and Wilson L: Microtubules as a target for anticancer drugs. Nat Rev Cancer 4: 253-265, 2004.

22. Bai R, Nguyen TL, Burnett JC, Atasoylu O, Munro MH, Pettit GR, Smith AB III, Gussio R and Hamel E: Interactions of halichondrin B and eribulin with tubulin. J Chem Inf Model 51: 1393-1404, 2011.

23. Nogales E, Wolf SG, Khan IA, Luduena RF and Downing KH: Structure of tubulin at $6.5 \mathrm{~A}$ and location of the taxol-binding site. Nature 375: 424-427, 1995.

24. Bai RL, Pettit GR and Hamel E: Binding of dolastatin 10 to tubulin at a distinct site for peptide antimitotic agents near the exchangeable nucleotide and vinca alkaloid sites. J Biol Chem 265: 17141-17149, 1990.

25. Dezső Z, Oestreicher J, Weaver A, Santiago S, Agoulnik S, Chow J, Oda Y and Funahashi Y: Gene expression profiling reveals epithelial mesenchymal transition (EMT) genes can selectively differentiate eribulin sensitive breast cancer cells. PLoS One 9: e106131, 2014.

26. Mendelsohn W: The significance of abnormal mitosis in the development of malignancy. Am J Cancer 24: 626-636, 1935.

27. Miki S, Imamichi S, Fujimori H, Tomiyama A, Fujimoto K, Satomi K, Matsushita Y, Matsuzaki S, Takahashi M, Ishikawa E, et al: Concomitant administration of radiation with eribulin improves the survival of mice harboring intracerebral glioblastoma. Cancer Sci 109: 2275-2285, 2018.

28. Swami U, Chaudhary I, Ghalib MH and Goel S: Eribulin-A review of preclinical and clinical studies. Crit Rev Oncol Hematol 81: 163-184, 2012.

29. Wilson L, Lopus M, Miller HP, Azarenko O, Riffle S, Smith JA and Jordan MA: Effects of eribulin on microtubule binding and dynamic instability are strengthened in the absence of the beta III tubulin isotype. Biochemistry 54: 6482-6489, 2015.

30. Person F, Wilczak W, Hube-Magg C, Burdelski C, Möller-Koop C, Simon R, Noriega M, Sauter G, Steurer S, Burdak-Rothkamm S and Jacobsen F: Prevalence of beta III-tubulin (TUBB3) expression in human normal tissues and cancers. Tumour Biol 39: 1010428317712166, 2017.

31. Koh Y, Jang B, Han SW, Kim TM, Oh DY, Lee SH, Kang CH, Kim DW, Im SA, Chung DH, et al: Expression of class III beta-tubulin correlates with unfavorable survival outcome in patients with resected non-small cell lung cancer. J Thorac Oncol 5: 320-325, 2010

32. Lebok P, Ozturk M, Heilenkotter U, Jaenicke F, Müller V, Paluchowski P, Geist S, Wilke C, Burandt E, Lebeau A, et al: High levels of class III beta-tubulin expression are associated with aggressive tumor features in breast cancer. Oncol Lett 11: 1987-1994, 2016.

33. Hinsch A, Chaker A, Burdelski C, Koop C, Tsourlakis MC, Steurer S, Rink M, Eichenauer TS, Wilczak W, Wittmer C, et al: $\beta$ III-tubulin overexpression is linked to aggressive tumor features and genetic instability in urinary bladder cancer. Hum Pathol 61: 210-220, 2017. 
34. Loeser H, Schallenberg S, von Winterfeld M, Tharun L, Alakus H, Hölscher A, Bollschweiler E, Buettner R, Zander T and Quaas A: High protein and mRNA expression levels of TUBB3 (class III ss-tubulin) are associated with aggressive tumor features in esophageal adenocarcinomas. Oncotarget 8: 115179-115189, 2017.

35. Nienstedt JC, Grobe A, Clauditz T, Simon R, Muenscher A Knecht R, Sauter G, Moebius C, Blessmann M, Heiland M and Pflug C: High-level betaIII-tubulin overexpression occurs in most head and neck cancers but is unrelated to clinical outcome. J Oral Pathol Med 46: 986-990, 2017.

36. Bachurski CJ, Theodorakis NG, Coulson RM and Cleveland DW: An amino-terminal tetrapeptide specifies cotranslational degradation of beta-tubulin but not alpha-tubulin mRNAs. Mol Cell Biol 14: 4076-4086, 1994.
37. Stargell LA, Heruth DP, Gaertig J and Gorovsky MA: Drugs affecting microtubule dynamics increase alpha-tubulin mRNA accumulation via transcription in Tetrahymena thermophila. Mol Cell Biol 12: 1443-1450, 1992.

38. Arnold SM, Moon J, Williamson SK, Atkins JN, Ou SH, LeBlanc M and Urba SG: Phase II evaluation of eribulin mesylate (E7389, NSC 707389) in patients with metastatic or recurrent squamous cell carcinoma of the head and neck: Southwest Oncology Group trial S0618. Invest New Drugs 29: 352-359, 2011.

This work is licensed under a Creative Commons Attribution-NonCommercial-NoDerivatives 4.0 International (CC BY-NC-ND 4.0) License. 